\title{
Growers prefer personal delivery of UC information
}

\author{
Richard P. Buchner $\square \quad$ James I. Grieshop \\ William H. Krueger $\square \quad$ William H. Olson \\ ] Joseph H. Connell \\ Carolyn Pickel ๖ John Edstrom 」 Frank T. Yoshikawa
}

The success of California agriculture depends on the effective delivery and adoption of useful information. Traditionally, Cooperative Extension has stressed the use of "multipliers" including pest control advisors and private consultants as an effective way to widely distribute information. However, results of a study examining the regional reach of information for tree crop farmers in a six-county area suggests such a strategy may not be as effective as presumed. Growers contacted PCAs, chemical representatives and private consultants more often than farm advisors, but considered farm advisors more useful information sources. Cooperative Extension and other agricultural educators must learn more about how farmers acquire information and what influences their adoption of new practices.

Agricultural producers depend on a variety of resources including water, capital, labor. Successful growers also require timely and useful information for making decisions. Traditionally, growers have relied on personal experience, other farmers, and Cooperative Extension in making agricultural management decisions. More recently, information has become available from other sources such as Pest Control Advisors (PCAs), private consultants and the electronic media.

Research-based information generated by UC's Division of Agriculture and Natural Resources is often noted as contributing to the historically high yield and quality of California crops.
In particular, Cooperative Extension advisors, have played vital and significant roles in disseminating this information. This study attempted to assess the impacts of research and information dissemination efforts by $\mathrm{CE}$ advisors, specialists and campus-based researchers for a large and integrated growing region.

Our goal was to assess how information developed and disseminated by UC was applied to farmers' decision and management systems. We assessed the use of information for three crops - almonds, walnuts and prunes - in a six-county growing region of Northern California. Given the importance of this growing region, information gathered here may prove instructive for the state's agricultural industry, especially for agricultural educators.

The production of walnuts, almonds and prunes in six of
California's Upper Sacramento Valley counties accounts for nearly one-third of all of California's crop production. In 1992, an estimated 1,900 growers in Sutter, Yuba, Butte, Glenn, Colusa and Tehama counties managed $32 \%$ of the walnut, $21 \%$ of the almond and $80 \%$ of the prune acreage statewide. Market value for these three commodities for the year exceeded $\$ 369$ million, or $32 \%$ of the statewide total of $\$ 1.1$ billion (table 1).

\section{New management practices}

We studied six management practices: planting, rootstock and variety selection, pruning, pest management, potassium application and irrigation techniques. All are areas in which significant efforts have been made over the years to establish and promote new practices. The logical next step was to measure their adoption by growers.

TABLE 1. Acreage and value (in millions of dollars) of almonds, prunes, walnuts for state and region, 1991-92

\begin{tabular}{|c|c|c|c|c|c|c|}
\hline \multirow[b]{2}{*}{ Crop } & \multicolumn{2}{|c|}{ State } & \multicolumn{2}{|c|}{ Region } & \multicolumn{2}{|c|}{$\begin{array}{c}\text { Regional } \\
\text { percent of state total }\end{array}$} \\
\hline & Acreage & Value & Acreage & Value & Acreage & Value \\
\hline & \multicolumn{2}{|r|}{$\$$} & \multirow[b]{2}{*}{202,124} & $\$$ & \multicolumn{2}{|c|}{ \% } \\
\hline All & 652,050 & $1,137.9$ & & 368.1 & 31 & 32.4 \\
\hline Almonds & 390,240 & 687.6 & 80,657 & 120.4 & 20.7 & 17.5 \\
\hline Prunes & 80,386 & 175.8 & 64,062 & 148.9 & 80 & 84.7 \\
\hline \multirow[t]{2}{*}{ Walnuts } & 181,424 & 274.5 & 57,405 & 98.8 & 32 & 35.9 \\
\hline & \multicolumn{2}{|c|}{$\begin{array}{c}\text { Estimated } \\
\text { no. growers }\end{array}$} & No. surveyed & \multicolumn{2}{|c|}{$\begin{array}{l}\text { No. responses } \\
\text { of total }\end{array}$} & $\begin{array}{c}\text { Return } \\
\text { by county }\end{array}$ \\
\hline & \multirow{2}{*}{\multicolumn{2}{|c|}{1,900}} & & \multirow{2}{*}{\multicolumn{2}{|c|}{$200(10.5 \%)$}} & $\%$ \\
\hline Region & & & $476(25 \%)$ & & & - \\
\hline \multicolumn{7}{|l|}{ County: } \\
\hline Butte & \multicolumn{2}{|c|}{532} & $134(28 \%)$ & \multicolumn{2}{|c|}{$76(39 \%)$} & 58 \\
\hline Colusa & \multicolumn{2}{|c|}{190} & $47(10 \%)$ & \multicolumn{2}{|c|}{$25(12.5 \%)$} & 53 \\
\hline Glenn & \multicolumn{2}{|c|}{190} & $46(10 \%)$ & \multicolumn{2}{|c|}{$25(12.5 \%)$} & 61 \\
\hline Sutter-Yuba & \multicolumn{2}{|c|}{628} & $158(33 \%)$ & \multicolumn{2}{|c|}{$44(22 \%)$} & 28 \\
\hline Tehama & \multicolumn{2}{|c|}{360} & $191(19 \%)$ & \multicolumn{2}{|c|}{$28(14 \%)$} & 27 \\
\hline
\end{tabular}


Planting. Planting practices refer specifically to increases in the number of trees per acre and their planting configuration. Depending upon the commodity, walnut, almond or prune trees can be planted in square, rectangle, equilateral triangle, or hedgerow configurations. Changes in planting density and configuration influence early production, yield, and how the orchard will be managed.

Variety / rootstock. Prune, almond and walnut trees are grafted so that the bearing variety is genetically different from the rootstock. This feature gives growers the option of selecting a pairing of rootstocks and varieties well adapted to a particular area. Research conducted by UCCE comparing variety/rootstock performance and yield has enabled growers to select improved varieties.

Pruning. Pruning practices are used to manipulate a tree's canopy in order to achieve a particular outcome Minimum and long (or intermediate) pruning remove less wood to encourage earlier fruit or nut production. Alternate year pruning and mechanical pruning are techniques used to reduce pruning costs. Modified central leader is a tree-training practice used in walnut culture to develop a structurally strong, open-canopied tree.

Pest management. Integrated Pest Management (IPM) is a long-term management strategy that incorporates a variety of techniques for coping with pest problems. Two IPM tools used for tree crops are monitoring insect activity with insect traps and predicting insect growth and development using degree days. These two practices were singled out as indicators of technology adoption.

\section{Potassium appli-} cation. The commonly accepted practice for correcting potassium deficiencies in soils relies on "massive" band applications drilled (or shanked) into soil every 4 to 5 years. Because this practice is expensive, growers have been reluctant to use it. Research aimed at trying to develop effective and economically acceptable alternatives has included drip application; foliar sprays for prunes; and low-rate maintenance, surface-banded application.

Irrigation technique. The study focused on drip and microsprinkler irrigation systems and the need for water conservation. Drip and microsprinklers are low-flow, low-pressure irrigation systems designed to apply small amounts of water frequently to specific areas.

\section{Grower survey}

In 1992 we developed and administered a pilot survey to selected growers within the test area. We incorporated changes and produced an eight-page booklet of 44 questions that could be completed in approximately 30 minutes. Questions were primarily "forced choice" (e.g., Do you 'strongly agree' or 'strongly disagree'?) along with a small number of questions that respondents were free to answer with their own words. The questions were organized into seven groups: general background and identification of information sources followed by planting practices, rootstocks and varieties,

\begin{abstract}
Alternate-year pruning is a technique used to reduce pruning costs. Pruning was one of six management practices studied to measure growers' adoption of practices recommended by UC.
\end{abstract}

pruning practices, pest management, potassium fertilization and drip/ microsprinkler irrigation.

We randomly selected a $25 \%$ sample $(n=476)$ of the estimated 1,900 walnut, almond and / or prune growers in the region from grower lists maintained by county $C E$ offices and county agricultural commissioners for Glenn and Tehama counties only. The sample was drawn by selecting every fourth name from available lists, which insured a representative and presumably unbiased random sample (table 2). The CE lists included growers known to $C E$ who had at one time indicated a desire to be on the list. Commissioner lists were developed from pesticide use reports in each county and included only growers who use reportable chemical pesticides. The use of two lists was a concern to the degree that they may have contained vastly different grower populations. Comparison of the two lists in Glenn and Tehama counties, 


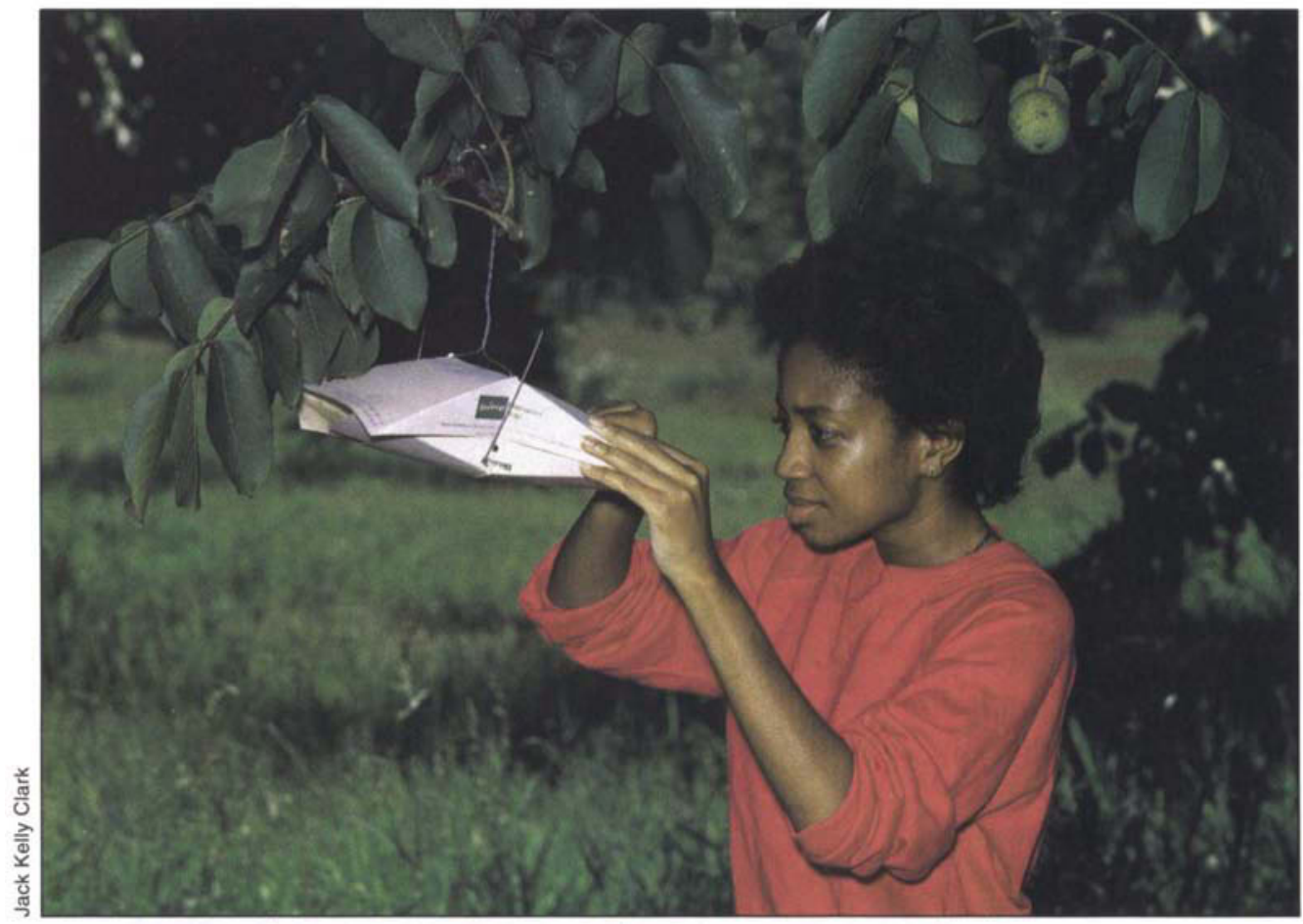

Monitoring insect activity with insect traps is an Integrated Pest Management method. Traps were used by $84 \%$ of walnut growers, $69 \%$ of almond growers and $52 \%$ of prune growers. however, indicated that most names appeared on both lists, an overlap that suggests that both lists contain essentially the same grower population.

Surveys were mailed to growers with a self-addressed stamped envelope and accompanying letter signed by each local farm advisor. To encourage participation, respondents were entered into a drawing for free UC publications if they completed and returned the survey. Participants were advised that their responses were confidential. Two weeks after the initial mailing, a reminder letter was sent. Returned surveys were re- viewed for completeness; clearly unacceptable surveys (respondent no longer farming or responses illegible) were not included in the analysis. Acceptable survey responses were coded for computer input and statistically analyzed.

\section{Growers respond}

The results are presented in three sections: a profile of respondents, respondents' use of and access to agricultural information, and respondents use of information and adoption of technology/practice for the six areas of tree crop management.
A total of 210 of the 476 mailed surveys were returned; of these, 200 were usable, a $41 \%$ return rate for the survey and a $10 \%$ sample for the estimated 1,900 growers in the six-county area (table 2). Variations in returned surveys by county were noted. The reasons for lower return rates for Sutter/Yuba and Tehama are not clear. One possible explanation is that in recent years these counties have had CE programs in transition, which may affect growers' awareness, trust and subsequent participation.

Sample profile. Within counties, respondents (fig. 1) were reasonably well distributed across commodities of walnut, almond and / or prune farmers.

In relation to tree crops grown, $63 \%$ farmed a single commodity while the remaining $37 \%$ farmed some combination of almonds, walnuts and/or prunes (fig. 2). On average, growers farmed 129 acres of prunes, 121 acres of walnuts and 278 acres of almonds. Roughly one-third of the respondents had less than 49 acres, another third farmed 50 to 199 acres and the remaining third had more than 200 acres. More than $60 \%$ of the respondents farmed in Butte, Sutter or Yuba counties, while $39 \%$ farmed in Colusa, Glenn or Tehama counties. Only $14 \%$ reported farming in more than one county.

Nearly $60 \%$ were over 50 years old, with $27 \%$ between the ages of 40 to 49 , and the remaining $13 \%$ between 30 to 39 years old. None was younger than 30 . This may be due partly to senior family members being more involved

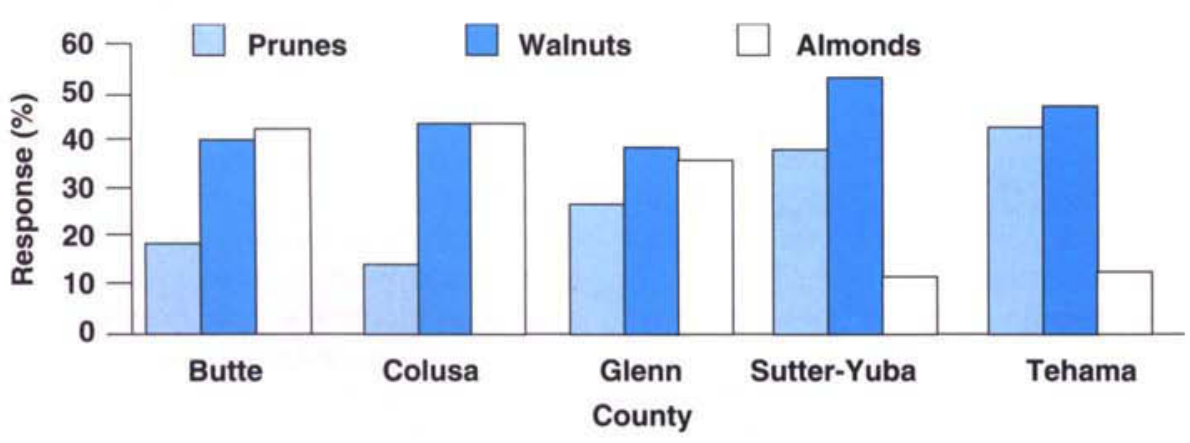

Fig. 1. Percent of response by crop by county of residence.

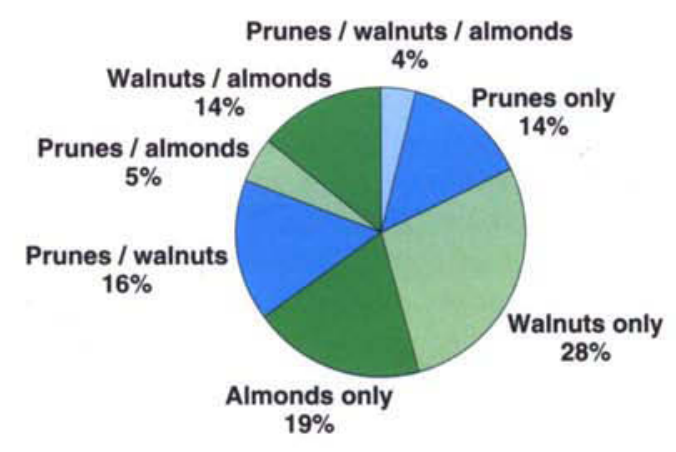

Fig. 2. Growers by commodity for all counties surveyed. 
in office management procedures and therefore more likely to respond to surveys, and younger family members being more involved in field activities. These figures conform with other age, education and ownership profiles for California.

The majority of respondents were well educated: $82 \%$ had attended college or earned a college degree $(15 \%$ had graduate degrees, $37 \%$ completed a 4-year degree and $28 \%$ had college experience). Only $18 \%$ indicated high school-or-less classroom education. Educational levels varied among counties: Butte County (92\%), followed by Colusa (83\%), Glenn (81\%), Tehama $(76 \%)$ and Sutter/Yuba (66\%), had the most respondents with at least some college education. Butte County has a 4-year state university, which may explain the higher levels of college experience.

A large percentage $(84 \%)$ of farms were family operations - sole owners, partnerships or corporations. Only $4 \%$ described their operation as a limited partnership, property management or non-family corporation. The remaining $12 \%$ described their farms as corporations operated by management companies or various combinations of tenant sibling or lease agreements.

\section{Where growers get information}

A major goal of this study was to determine where growers get information about specific tree crop management technologies and practices and to assess their views on the usefulness and relative importance of information services.

Over the six-county area, growers reported they generally obtain crop/ cultural management information from farm advisors. The PCAs, chemical representatives and private consultants were contacted more often (once per month) than farm advisors, but farm advisors were considered more useful information sources than other farmers and PCAs. Family members, private consultants, farm suppliers and grower associates were consulted infrequently while employees, bankers and CPAs were seldom consulted. Manuals or books were also cited as sources, suggesting that UC's role may be greater than indicated since many of these publications are written by specialists and farm advisors and many PCAs also obtain information from farm advisors.

Growers' reported low use of private consultants - apart from PCAs - is noteworthy but does not necessarily reflect their perceived usefulness. Private consultants provide valuable management information, but usually not on an ongoing basis because such services can be relatively expensive for a family farm.

Growers reported low use of TV (including video) and radio for agricultural information (table 3). It is not clear why more growers do not utilize the electronic media for agricultural information. They may regard these more for their entertainment value than as a potential source of useful information. Although growers reported using computers (33\%), they use them predominately for accounting purposes, including bookkeeping, records, budget and payroll. In the area surveyed, computers are not typically used as tools for education or orchard management.

Additional study is needed to assess whether radio/ TV/video and computers represent viable techniques to extend agricultural information, and under what conditions. As communication technologies change and new ones are developed, questions about how growers utilize and assimilate information will become critical in the design, planning and delivery of information-based programs. As educators, farm advisors need both to master new technologies, such as computers, and more efficiently utilize traditional ones, such as TV and radio. At the same time, advisors and specialists may have to include efforts to disseminate information about accessing these new sources of knowledge.

\section{Adopting new techniques}

We also surveyed growers' adoption of tree management practices and their information sources. Since there were multiple planting, pruning, and potassium application practices depending on the crop, a range of percent awareness or use is indicated in table 4 . This report is a summary of general findings, rather than a practice by practice analysis. Table 5 summarizes sources of management practice information reported as important (pruning not included).

Tree configuration and density. In the past 20 years, UC pomologists have systematically researched alternative tree planting systems. These systems involve increasing tree densities using square/ rectangular, or equilateral triangle configurations and a

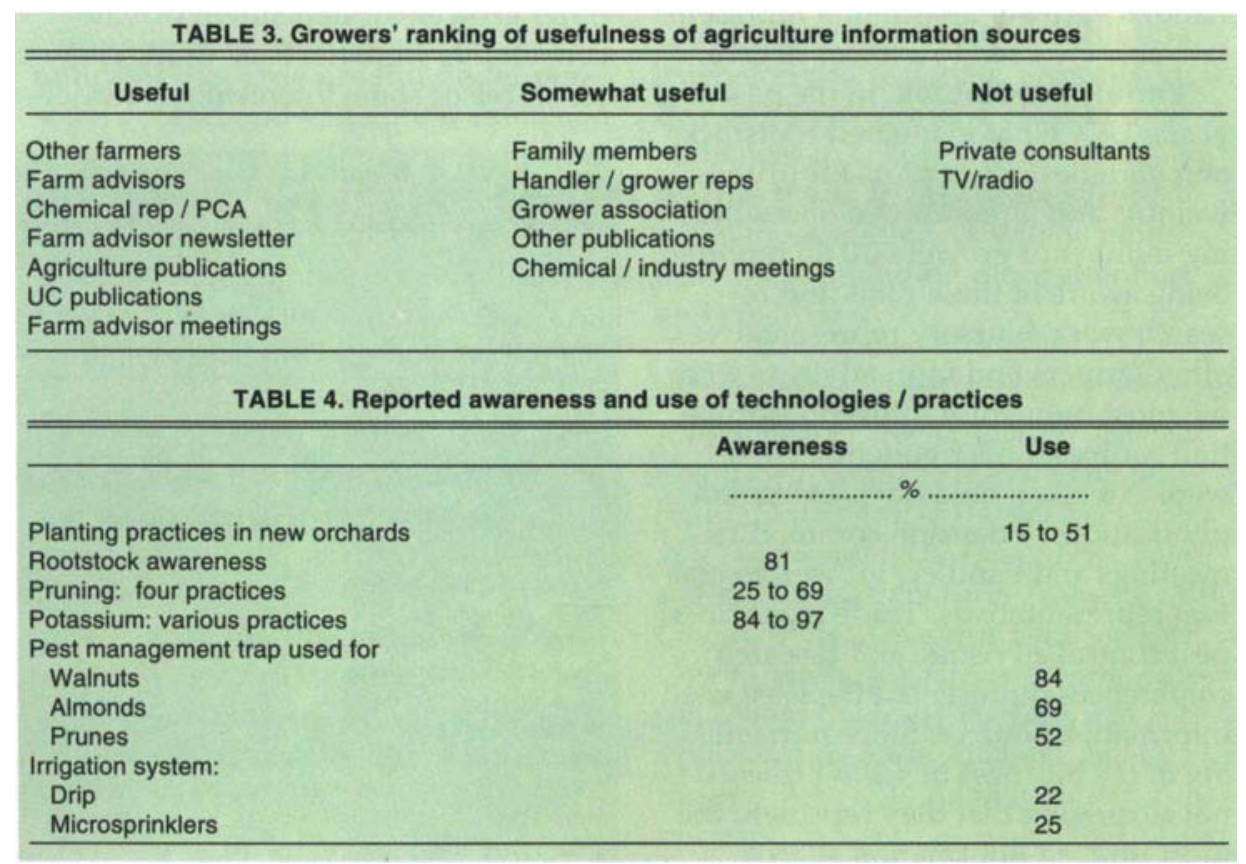




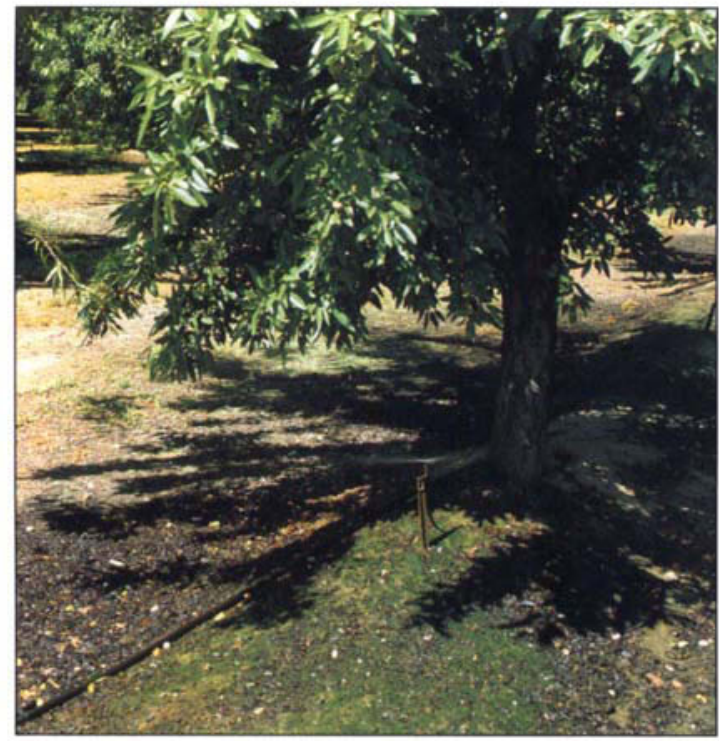

Other farmers and irrigation dealers were the most utilized sources of information about microsprinklers.

somewhat unique configuration that places trees in a hedgerow. Results indicate that new orchards are being planted at higher densities than before. The principal factors that influence configuration and density decisions are earlier return on investment, increased production, opportunities for mechanization, and soil considerations. Personal experience was the most important source of information for growers. Growers also reported that other farmers, farm advisors and field days represented useful information sources. Trade magazines and handler/grower association representatives were used to a lesser degree.

Variety / rootstock. In the past 15 years, UCCE has evaluated rootstocks and varieties in test plots for prunes, walnuts and almonds. An overwhelming number of growers $(81 \%)$ reported being aware of these plots and research work. Nursery representatives, other farmers and farm advisors were the most frequently utilized information sources. Less frequently cited were extension field days, extension publications, extension commodity meetings and handler/grower association representatives. Trade magazines, pest control advisors, and research conferences represented the least used information sources. Since nurseries are in the business of selling trees, it is not surprising that they represent the most utilized information source.
Potassium application practices. UC developed the standard technique of "massive" soil applications every 4 to 5 years to correct potassium deficiencies in soils. Newer practices include foliar treatments, banded maintenance applications, drip zone placement, and injection into drip systems. Extension information, and subsequent grower adoption of these methods, has been very good. Depending upon the specific method, 84 to $97 \%$ of the respondents were aware of the new practices.

Farm advisors were the most commonly utilized source of information regarding correction of potassium deficiency, followed by farm advisor field days, PCA recommendations, other farmers and fertilizer dealers. Trade magazines were the least utilized source.

\section{Integrated pest management.} Grower use of insect traps and/or degree-days indicated adoption of this IPM technology. Traps were used by $84 \%$ of the walnut growers, $69 \%$ of almond growers and $52 \%$ of prune growers. The higher rate of trap use in the nut crops, compared to prunes, reflects more insect damage pressure.

Growers reported that farm advisor newsletters were the most useful source for insect development/ degreeday information, followed by chemical representatives, farm advisors and other growers. Independent private consultants were the least used. This result raises some interesting consider- ations because UCCE depends on PCAs and other "multipliers" to further extend its information. This survey data suggest that this strategy might need to be reevaluated since growers report that farm advisors are their leading source of information. Any reevaluation should examine the roles of secondary information disseminators.

\section{Drip and microsprinkler irriga-}

tion. Reportedly $22 \%$ of the surveyed growers used drip systems, while $25 \%$ used microsprinklers. A smaller percentage anticipated using drip or microsprinklers in the future $(\mathbf{1 3 . 2} \%$ and $17.3 \%$, respectively). In contrast, nearly $17 \%$ of growers had used but later abandoned drip irrigation and $9 \%$ had abandoned microsprinklers.

Information sources influencing irrigation decisions differed depending upon the system. For drip systems, UC's Nickels Field Day was the most frequently used source, followed by other farmers, farm advisor newsletters and contacts, and farm advisor field days. Irrigation dealers and trade magazines were used to a lesser extent. Nickels Field Day is held annually to demonstrate new techniques in tree culture. The Nickels Field Day was used by $21 \%$ of growers for drip information, but only $3 \%$ cited it as a source for microsprinkler information. This is no doubt due to the emphasis on drip irrigation at the Nickels location. For microsprinklers, other farmers and irrigation dealers were the

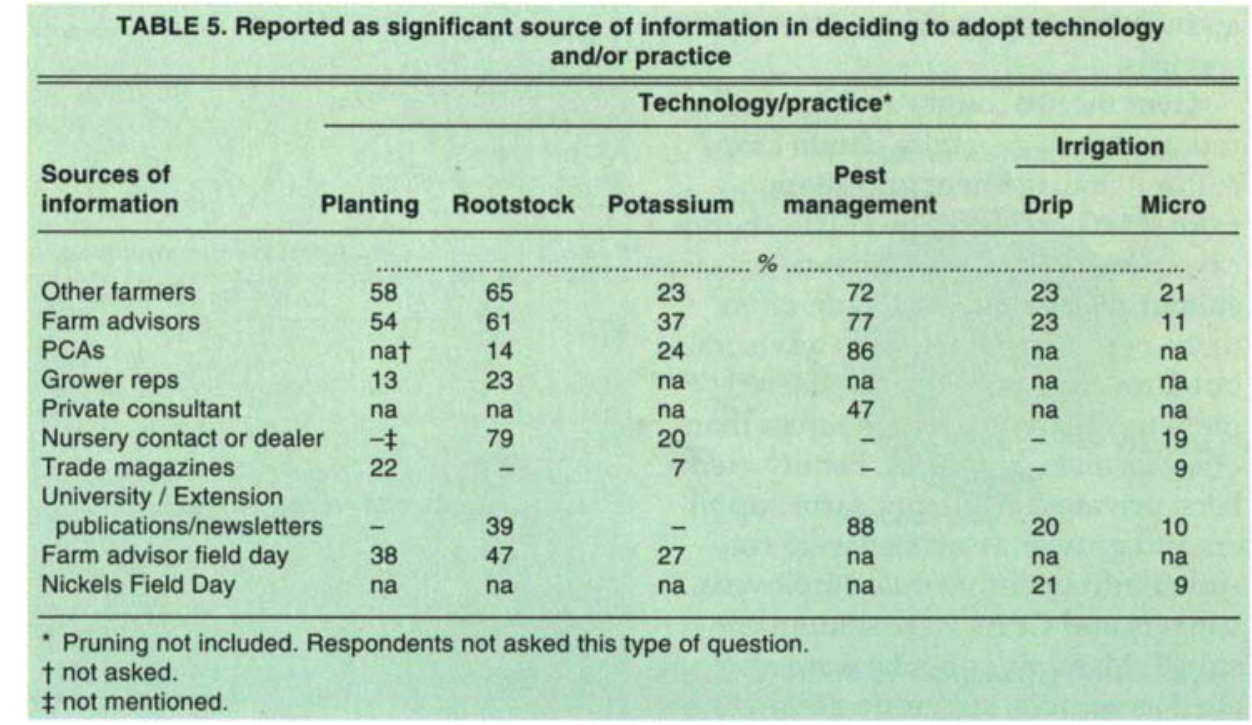



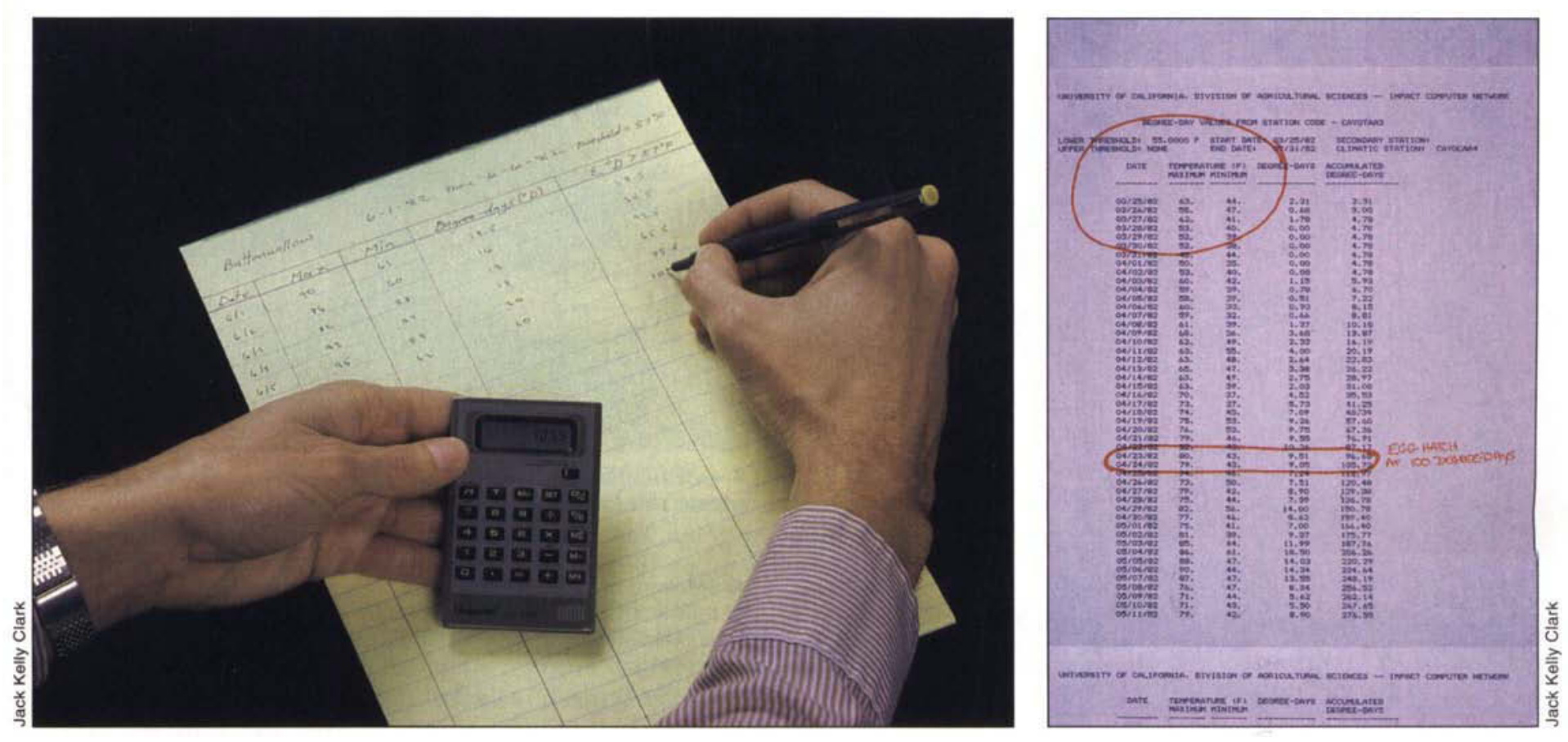

UC promotes using degree days to predict insect growth and development. Growers reported that

farm advisor newsletters were the most useful source for insect development/degree-day information, followed by chemical representatives, farm advisors and other growers.

most utilized sources. Farm advisor contacts, trade magazines and farm advisor field days were not used as often.

\section{Developing delivery systems}

Multiple mechanisms exist for disseminating and delivering information to California farmers. These include farm advisor activities, newsletters, farm journals, contact with other farmers, and other agricultural support services. No single method for extending information can be relied on; our research found that growers are selective, searching and questioning both their sources and their information. Results also indicate that growers select different sources depending on the crop management practices. Information methods that involve personal contact are highly rated by growers. Farm advisors are an important direct and indirect information source for growers. Other farmers also represent a valuable source of information.

One surprising finding of our study was the lower than anticipated rating for sources of information regarded as "multipliers" (e.g., PCAs, consultants, bankers, sales personnel). Although Extension traditionally has stressed the use of these multipliers as an effective way to widely distribute informa- tion, our data suggest such a strategy may not be as effective as presumed. The potentially contradictory roles of these multipliers should also be examined. Do "multipliers" perform as "gate-keepers" or as extenders of information?

Development of an effective information delivery system remains a $\mathrm{dy}$ namic process, but one that will become more important as the extension system shrinks in terms of financial support and personnel. Our research indicates that growers still prefer personal contact and value their extension contacts and printed materials. However, as fewer resources become available to support farm visits, CE needs to explore alternatives. It must learn how to take advantage of electronic media, such as the Internet, World Wide Web, and distance education by satellite. Although growers in our study reported low use of electronic media, its use is anticipated to increase and will present new opportunities for extending information.

This dynamic situation presents major challenges for agricultural educators statewide - not only extension and school educators, but PCAs, consultants, and others concerned with providing timely and useful agricul- tural information. Our results indicate that, as the systems of information delivery and grower audiences change, more attention must be given to the means and processes for delivering information. Research must include efforts to evaluate why some methods are not widely used by growers, and how to enhance their usefulness and adoption. It has yet to be determined how these methods can be improved and / or adapted to meet grower needs.

Agricultural educators, including extension professionals, typically view themselves as working close to their audiences to ensure that the message reaches them. In the future, efforts to reach those audiences will be more difficult, demanding more attention and creativity.

R.P. Buchner is Farm Advisor, Tehama County; J.I. Grieshop is Extension Specialist, Department of Human and Community Development, UC Davis; J.H. Connell and W.H. Olson are Farm Advisors, Butte County; W.H. Krueger is Farm Advisor, Glenn County; J. Edstrom is Farm Advisor, Colusa County; J.K. Hasey and F.T. Yoshikawa are Farm Advisors, and $C$. Pickel is Area IPM Advisor, Sutter-Yuba counties. 